\title{
A Edição no Brasil
}

Fábio Maria De Mattia

Professor-Adjunto do Departamento de Direito Civil da Faculdade de Direito da

Universidade de Sāo Paulo

\begin{abstract}
RESUMO: 1. Introduçāo. 2. Institutos jurídicos através dos quais a obra intelectual escrita é comunicada ao público. 3. Valor subsidíario das normas do contrato de edição. 4. Diretos do Autor: a) de natureza patrimonial e b) de natureza moral. 5. Direitos do Editor: a) de natureza patrimonial e b) de natureza moral. 6. Perspectivas para um equilíbrio no relacionamento entre o autor e o editor. Os contratos-tipo, as negociaçôes coletivas e as normas de ordem pública.
\end{abstract}

\section{1 - Introdução}

O tema desta palestra insere-se no capítulo destinado aos EDITORES onde são abordados os assuntos: a importância dos editores na América Latina; a edição no Brasil; os editores-membros ou não das sociedades de direitos de autor e dos direitos conexos; e as experiências européias de cooperação com os editores.

A despeito do conceito amplo da palavra EDIÇĀO, circunscrevemo-nos à análise da obra gráfica dita literária ou escrita diferenciada da edição de partitura musical, da ediçaao fonográfica, da edição de películas cinematográficas, da edição fotográfica etc.

O desenvolvimento do tema se dará com a análise do sistema positivo e a indicaçāo de complementaçōes ou de inovações necessárias à atualização da legislação e para manter equilíbrio nas relaçōes contratuais entre autor e editor.

\section{2 - Institutos jurídicos através dos quais a obra intelectual escrita é comunica- da ao público - diferença entre o direito de edição e o contrato de edição.}

São três os institutos jurídicos à disposiçāo dos autores e editores: o contrato de ediçāo, o contrato de licença e a cessão do direito patrimonial de autorr. Existe a exceção da licença obrigatória ou legal.

O contrato de ediçāo pressupõe a transferência do direito de utilização do direito patrimonial ao editor e tem como característica constante a exclusivida- 
de com que é investido o editor nesta utilização. O editor investe-se do "ius prohibitionis" pertencente ao autor.

O contrato de licença diferencia-se do contrato de edição pela ausência do caráter de exclusividade, o direito exclusivo é sempre do autor, autorizadas utilizaçōes coexistentes da própria obra, mas limitadas nó ternpo e pelas finalidades do contrato.

O contrato de edição é regulado nos artigos 57 a 72 da Lei no 5.988 , de 14 de dezembro de 1973, nenhuma referência existindo com relação ao contrato de licença que contudo se rege pelas normas aplicáveis ao contrato de edição naquilo que for com este compatível.

O contrato de cessão do direito patrimonial de autor consiste na transferência do direito patrimonial de autor ao editor, que, transformando-se em cessionário, impede que aquele possa se utilizar economicamente da obra.

A cessão não impede que o autor receba direitos autorais, mas não terá mais prerrogativas de disposição sobre a obra, que terá o cessionário como titular, tanto do direito de dispor da obra, como de utilizá-la com fins econômicos.

A cessão é regulada na Lei no 5.988 nos artigos 52 a 56.

Há uma tendência que parece predominante entre os especialistas brasileiros a favor da supressão do instituto da Cessāo e sua substituição pela Concessão nos termos da legislação autoral alemã, segundo a qual o titular só pode autorizar a utilização da obra, sem se desfazer da titularidade desse direito. Tal posição de política legislativa protege o titular contra as cessões anti-econômicas, os negócios jurídicos aperfeiçoados antes de a obra adquirir sucesso, quando o titular estaria despojado de condiçōes para apurar o verdadeiro preço de seu direito.

Precedentes contra a cessão de direito patrimonial de autor e direitos conexos encontramos na legislação que regula a profissāo de artista e de técnico em espetáculos de diversões, artigo 13 da Lei no 6.533, de 24 de maio de 1978, e na que regula a profissão de radialista, artigo 17 da Lei no 6.615 , de 16 de dezembro de 1978.

É necessário também ressaltar a possibilidade de a obra vir a ser colocada à disposição do público, sem que se configure contratação entre autor e editor, na eventualidade da licença legal ou obrigatória, cujo regime está em plena evolução. A esse respeito as disposições da Convenção de Berna e da Convenção Universal de Direito de Autor com as disposições introduzidas pela Revi- 
são de Paris, destinadas a permitir traduções quando se impuserem necessidades de ordem didática, científica, de pesquisa.

A Lei no 5.988 atribui ao CNDA - Conselho Nacional de Direito Autoral competência para manifestar-se sobre os pedidos de licenças compulsórias previstas em Tratados e Convenções Internacionais (artigo 117, inciso VIII). Ao CNDA jamais foi submetido qualquer pedido.

Para terminar este tópico é conveniente distinguir o direito de edição do contrato de edição.

Com o negócio jurídico que autoriza terceiro a reproduzir a obra investese este do direito de edição cujo conteúdo limita o uso que o autor pode fazer de sua obra (contrato de edição) ou garante ao editor a prerrogativa de também reproduzir a obra (contrato de licença).

\section{3 - Valor subsidiário das nomas do contrato de edição}

As normas do contrato de edição aplicam-se a outros meios através dos quais os direitos de autor são objeto de comércio jurídico. Assim, as normas encontráveis no capítulo do contrado de edição na lei italiana são aplicáveis, também, a todos os contratos de cessão dos direitos de utilização econômica, por exemplo: conteúdo e duração do contrato; a respeito de direitos futuros eventualmente atribuídos por leis posteriores, exclusão dos direitos derivados de possíveis elaborações e transformações.

No direito brasileiro, também, as normas do contrato de edição são utilizadas em outros negócios jurídicos ou no chamado contrato de ediçāo tendo como objeto outras obras protegidas pela Lei de Direito de Autor.

\section{4 - Direitos do autor. De natureza patrimonial e de natureza moral}

\section{A) Direitos do autor de natureza patrimonial}

Tal enunciado se circunscreve à retribuição econômica do autor que pode ser examinada sob três aspectos:

1) modalidades de retribuição econômica;

2) prestação de contas;

3) pagamento dos direitos de autor.

$\mathrm{Na}$ análise das modalidades de retribuição econômica, deve ser esclarecido, quanto ao cálculo da remuneração, que o autor é remunerado quer através de uma quantia única, quer pelo pagamento de porcentagens. Esses dois modos 
de remuneração são, naturalmente, suscetíveis de modalidades. Convencionase, quase sempre, uma porcentagem sobre o preço de venda de cada exemplar a favor do autor, mediante acertos periódicos. Nada impede o pagamento antecipado do total dos direitos autorais, no sistema à forfait. Quanto a este sistema, é conveniente disposição legislativa autorizando que se circunscreva a uma edição ou a número limitado de tiragens a fim de se evitar que o autor se prejudique ao fixar a remuneração com antecedência antes do sucesso da obra. Este é um aspecto que merece melhor regulação legislativa entre nós.

Se, por acaso, o contrato de edição for omisso quanto à remuneração a ser paga pelo editor, o art. 60 da Lei no 5.988 determina que esta será arbitrada pelo Conselho Nacional de Direito Autoral.

Lacuna existente no direito brasileiro está na falta de regra determinando remuneração mínima nos termos do art. 1.355 do Código de Comércio da Colômbia ao dispor que o contrato de edição deve estipular a remuneração do autor que, contudo, não pode ser inferior a $10 \%$ do preço de venda ao público. $\mathrm{Na}$ falta de estipulação, esta porcentagem prevalecerá(*).

Sob o aspecto das modalidades da retribuição econômica são abordados os seguintes assuntos: porcentagem sobre o preço de venda, quantia previamente fixada e paga, o pagamento de direito de autor como elemento essencial do contrato, desconto do preço da encadernação, ação de revisão do valor pago a título de direito de autor, sobre quais exemplares incide a remuneração do autor quando fixada com base em porcentagem sobre cada exemplar vendido; modificaçōes no cálculo da remuneração do autor, melhoria da porcentagem do autor e adiantamento de pagamentos de direito de autor.

Destes itens devemos destacar um pela sua importância e pelos efeitos: ação de revisão do valor pago a título de direito de autor. É matéria ausente da legislaçāo brasileira e não pode ser esquecida na sua atualização. Será uma maneira de reequilibrar a posição do titular do direito em relação ao editor.

Trata-se da aplicaçāo da teoria da imprevisão.

É lamentável que o direito positivo brasileiro não adote a teoria da onerosidade excessiva com o objetivo de repor as partes contratantes em equilibrio.

Verificamos a importância da matéria para com o contrato de edição de acordo com o seu tratamento na lei francesa e a aplicação do instituto na Itália.

(*) O artigo 106 da Lei de Direito de Autor da Colômbia, de n" 23, de 28 de janciro de 1982, não mantevè o critério de ordem pública, não estipulou remuncração mínima, mas. no silêncio do contrato, a lei presume a estipulação de $20 \%$ ( vinte por cento). 
A situação, no Brasil, modificar-se-á uma vez aprovado o capítulo da onerosidade excessiva como está desenvolvido no Projeto de Código Civil.

$\mathrm{O}$ autor, muitas vezes, assina um contrato de edição com uma retribuição econômica irrisória. No futuro, quando forem efetuadas novas edições, se o contrato assim o estipular, a obra for aceita com sucesso pelo público, o autor arrepender-se-á do quantum pactuado.

Daí ser necessário estipular uma norma de ordem pública determinando, por exemplo, uma percentuagem mínima a ser paga ao autor nos moldes do artigo 1.355 do Código de Comércio da Colômbia, norma cogente, que estipula uma porcentagem mínima de dez por cento sobre o preço de venda ao público e, se o contrato previr duas ou mais edições, então a porcentagem mínima será de $15 \%$.

Subsídios podem ser obtidos na legislação francesa e italiana.

Na França a matriz é o artigo 37 da Lei de 1957 que sanciona um direito à revisão das condições do contrato quando a retribuição é feita no sistema de porcentagem e o autor sofre uma lesão de 7/12, em decorrência de uma previsão insuficiente dos benefícios da obra. O pedido de revisão só poderá ser formulado nos casos de obra cedida por meio de uma remuneração efetuada de uma única vez. A lesão será apreciada em consideração à exploração pelo cessionário do conjunto das obras do autor que se pretende lesado.

O artigo 37 da Lei de 1957 desejou outorgar aos juízes a possibilidade, em caso de lesão de mais de 7/12, de rever as condições dos contratos. Encontra-se, numa certa medida, nesse assunto, o poder disciplinar dos tribunais sobre certas profissōes.

O defeito da lei francesa é permitir a revisão levando-se em conta o conjunto da obra do autor e não quando tiver publicado apenas uma obra.

No direito italiano também se pode cogitar de uma ação de revisão da retribuição devida ao autor pela utilização econômica de sua obra intelectual, como se depara no artigo 124 da Lei n- 633 combinado com o artigo 1.467 do Código Civil italiano. A ação de revisão só é possível no caso de cessão através de remuneração forfaitaire.

Importante a regulação dos seguintes aspectos:

Prestaçāo de contas (a obrigação de prestar contas e o equilíbrio na prestaçāo de contas). 
Pagamento dos direitos de autor (época do pagamento, as garantias fornecidas ao autor com relação ao pagamento do preço, o pagamentos dos direitos de autor mesmo na eventualidade de não publicação por inadimplemento por parte do editor e sanção pelo não pagamento dos direitos de autor).

Para se aumentar a proteção necessária ao autor da obra intelectual ainda se impõem, numa reforma legislativa, as seguintes disposições legais:

a) regra prevendo prazo máximo de autorização para a reprodução das obras intelectuais nos contratos de edição e licença;

b) modificação a ser introduzida no artigo 64 da Lei no 5.988 explicitando tratar-se de norma cogente a que determina a numeração dos exemplares da obra reproduzida;

c) inserir na legislação norma instituindo critério para se considerar a edição ou tiragem como esgotada;

d) inserir na legislação norma regulando o modo de se liquidar o resíduo da tiragem ou edição.

Quanto ao item c, sugestão adequada é disposição legal nos moldes do art. 1.358, alínea $2^{2}$ do Código de Comércio da Colômbia: quando o número disponível de exemplares para a venda for inferior a dez por cento do total clos exemplares impressos na respectiva edição ou quando se configurar escassez da obra por retenção injustificada da mesma em poder do editor ou dos distribuidores.

Quanto ao item d, pelo artigo 69 da Lei no 5.988 , "enquanto não se esgotarem as edições a que tiver direito o editor, não poderá o autor dispor de sua obra". Numa reforma legislativa é conveniente permitir duas orientaçōes: a faculdade do autor ou do novo editor de adquirir os exemplares configuradores do resíduo da tiragem ou autorizar o autor a negociar nova edição com outro editor permitindo-se ao editor anterior continuar comercializando o resíduo. Como modelo são indicados os artigos 120 e 135 da Lei de Direitos de Autor da Colômbia, Lei no 23, de 28 de janeiro de 1982.

Tal regulação é necessária em face do argumento de que o autor não recupera sua liberdade de ação até o momento em que o último exemplar tenha sido alienado.

Em sendo dada a opção de compra, é necessário criar um mecanismo obrigando o editor a fornecer o número de exemplares em estoque para se evitar recusa no fornecimento por parte do editor com o objetivo de se beneficiar economicamente com o impasse criado. 


\section{B) Direitos de autor de natureza moral}

Muitas são as prerrogativas previstas no artigo 25 e que se encontram presentes quando o titular autoriza terceiro a publicar a obra. Entre elas: quanto ao direito de divulgação, ao direito de respeito à obra, ao direito à paternidade, quanto às relações entre o autor da obra anônima ou pseudônima e seu editor, mas, principalmente quanto ao direito de arrependimento.

Entendemos como prerrogativa de direito moral do autor a de ter preferência para aquisição dos exemplares invendáveis.

É outra lacuna existente no direito brasileiro que poderia ser sanada com o modelo constante do artigo 56 da Lei francesa de 1957 e artigos 133 e 134, no 5 da Lei italiana de 1941: ambas traçam regra para a venda abaixo do preço, com outorga de preferência na compra pelo autor e possibilidade de destruição dos exemplares. O editor só poderia vender os exemplares a preço abaixo do custo quando o autor tiver rejeitado a proposta do editor para adquiri-los pelo novo preço reduzido.

O artigo 103 da Lei peruana dá um parâmetro para tal exercício: reconhece que tanto o autor como o editor têm o direito de rescindir o contrato, se após três anos de publicada a edição não se tiverem vendido mais de dez por cento dos exemplares.

Quanto ao direito de arrependimento, não é regulado na nossa lei, mas apenas indicado no artigo 25 , inciso VI e parágrafo 3 ‥

Tal direito moral de autor pode ser exercitado, inclusive quando a obra for cedida e consiste na prerrogativa de retirá-la de circulação ou de lhe suspender qualquer forma de utilização já autorizada.

Para tanto deverá o autor indenizar o editor.

A álea dos cálculos seria evitada se os contratantes inserissem, em previsāo do arrependimento, cláusula penal não pura com a pré-avaliação das perdas e danos.

Urge regular tal instituto no direito de autor pátrio e como modelo podem ser utilizados os artigos 142 e 143 da Lei italiana de 1941 e 32 da Lei francesa.

Para se evitar abusos por parte do autor que, invocando o direito ao arrependimento, negocie a reprodução da obra com outro editor, impōe-se regra similar ao \$2" do artigo 32 da Lei francesa que investe o co-contratante, que sofreu a incidência do arrependimento, num direito de prioridade em virtude do 
qual ele poderá encarregar-se da publicação nas mesmas condiçōes pactuadas para publicação abortada.

$\mathrm{O}$ direito de arrependimento pode ser exercitado tanto quando dos preparativos de uma ediçāo, como quando os volumes já foram colocados à disposição do público, sem, todavia, poder forçar a entrada na residencia dos compradores de exemplares ou revistar as bibliotecas para retirar os livros.

É possível a configuração do direito de arrependimento nas obras em colaboração, pois a faculdade unilateral de arrependimento prevalece sobre a affectio societatis e o espírito de equipe que preside toda tarefa levada a efeito em comum.

\section{5) Direitos do editor de natureza patrimonial e de natureza moral}

\section{A) Direitos do editor de natureza patrimonial}

A matéria pode ser desenvolvida sob três aspectos: do autor;

1) o pacto de preferência à favor do editor com relação às obras futuras

2) a convenção de Viena de 12 de junho de 1973 e a proteção dos caracteres tipográficos e seu depósito internacional quanto à duração da proteção;

3) direito de tradução.

Quanto ao item 2, a regulamentação da tutela aos caracteres tipográficos tornou-se uma exigência inadiável, porque aumentou o número de plágios de criações tipográficas em decorrência da utilização de algumas invenções sensacionais no domínio da técnica, e mais, particularmente, da reprodução fotográfica dos sinais tipográficos.

Poderia ser impresso um livro com o seguinte comportamento da editora: reproduzir, fotograficamente, as páginas de um exemplar publicado por uma outra editora, no próprio país, ou no exterior, e com base nas cópias assim obtidas reimprimir o livro? No plano de direito de autor, não se hasitaria em responder pela negativa.

Quanto ao pacto de preferência a favor do editor, falta inserir no direito brasileiro de autor um conjunto de normas que regule cste instituto. A experiência da excelente disciplina do direito francês, a respeito, não deixou de criar impasses, razão pela qual, com base no ponto de maturidade atingido no direito francês, será possível regular adequadamente o assunto, entre nós, evitando os pontos críticos surgidos com a prática. 
$O$ editor pode pactuar com o autor a inserção de cláusula no contrato de ediçāo segundo a qual terá preferência na edição de obras futuras do autor.

O direito brasileiro, pelo artigo 54 da Lei no 5.988, cuida em limitar o prazo, dentro do qual valem as cessōes de obras futuras, a cinco anos, mas é lamentável que o dispositivo não obste a cessão de mais de cinco obras.

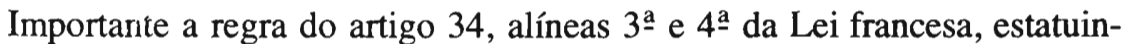
do que o editor deve utilizar a preferência dentro do prazo legal, permitindo, alínea $4^{\mathrm{a}}$, que $o$ autor possa rescindir o pacto de preferência quando o editor tiver recusado, sucessivamente, duas obras.

\section{B) Direitos do editor de natureza moral}

Deve-se a ADRIANO DE CUPIS o desenvolvimento dos direitos do editor sob o aspecto de direito moral, alinhavando-se entre outros:

1) o direito à paternidade do editor;

2) o direito moral do editor originário e derivado; e

3) o direito do editor protegido contra a concorrência ilícita.

Quanto ao primeiro item, o editor tem o direito de fazer-se reconhecer por todos pelo que é, ou seja, editor, empreendedor da publicação e utilização da abra. A sua qualidade de editor não pode ser desconhecida por ninguém. Ele tem direito à sua verdade pessoal, ao lado de qualquer outro, a par com o autor.

$\mathrm{O}$ direito à patemidade intelectual, no qual encontramos o direito moral do autor, não é senão um aspecto do direito, mais geral, à paternidade dos próprios atos, ao reconhecimento e respeito externo de tal paternidade, ao nãocomprometimento da própria verdade pessoal.

Ao autor pertence a paternidade da obra intelectuai e ao editor a paternidade do livro que é, simplesmente, o meio de difusão da obra intelectual.

O editor é, sempre, protegido contra o desconhecimento da sua qualidade de editor da obra, por exemplo, contra a compilação de um catálogo livreiro compreendendo algumas obras por ele editadas, sem a indicação ou com alteraçāo de seu nome.

Quanto ao segundo item, em alguma hipótese excepcional, o editor adquire, originariamente, a qualidade de autor, com base em um seu pessoal fato criativo, mas, ao invés, em regra, adquire derivativamente dita qualidade. 
Quando a obra cai em domínio público, o direito do editor é originário e não deriva daquele que se extinguiu do autor ou, então, dos seus sucessores.

Quanto ao terceiro item, direito do editor protegifo contra a concorrência ilícita, ocorre quando a forma ideada pelo editor é utilizada por um concorrente, desrespeita-se a proteção do direito à paternidade sobre a forma do livro.

Com isso a tutela do interesse do editor apresenta-se, em relação ao comportamento de terceiro que publica, sob a própria sigla editorial, uma ou mais obras com iguais características, quanto aos caracteres tipográficos, frontispício, papel, formato do livro, paginação e encadernação.

Se outro editor concorrente reproduz ou imita tal forma exterior do livro, mesmo que nāo crie confusão entre as obras, entre os respectivos autores, pode, todavia, criar confusão, no público adquirente, a respeito das atividades editoriais, sobre a procedência das obras etc.

\section{6) Perspectivas para um equilibrio no relacionamento entre o autor e o editor. as normas de ordem pública, os contratos-tipo e as negociaçōes coletivas}

Foram alinhavadas propostas de reformulação legislativa para fortalecer os direitos do autor, evitar os conflitos configuráveis entre autor e editor, pois o equilíbrio entre o autor e o editor depende da adequada regulamentaçăo legislativa da matéria, com o que se procura neutralizar a normal superioridade exercida pelo editor.

Daí a necessidade de o contrato de edição ser regulado com normas inderrogáveis, com o que se protegerá a parte economicamente mais fraca. Essas normas cogentes em matéria de contrato de edição justificam-se pelo interesse público. A lição de VAUNOIS é adequada: "la loi doit être impérative, autrement, elle est superflue".

O recurso para manter o equilíbrio nas relações contratuais entre o autor e o editor tem sido a utilização de contratos-tipo, quer a nível de esforço nacional, quer a nível internacional, impondo-se a necessidade de um trabalho de dimensões ilimitadas a favor da aceitação de contratos-tipo.

Os contratos-tipo a nível nacional devem ser o resultado de negociações coletivas com os interessados lutando pela consolidação de seus direitos.

Palestra proferida no "Curso Especializado de Formação em I)ireito de Autor e I)ireitos Conexos", em Brasília, aos 23 de abril de 1985, organizado pela () NIPI (Crganizatção Mundial da Propriedade Intelectual), SUISA (Sociedade Suíça do Direitos dos Autores de Obras Musicais), pelos Ministérios das Relaçóes Lxteriores e Ministério da (cultura através do CNDA - Conselho Nacional de I Direito Autoral. 